\title{
Use of Biologic Drugs for Treatment of Allergic Bronchopulmonary Aspergillosis
}

\author{
Saeed Albogami* \\ Consultant Pulmonologist, King Fahad Hospital, Saudi Arabia
}

Submission: September 29, 2021; Published: October 11, 2021

*Corresponding author: Saeed Albogami, MBBS, MD, FRCPC, FCCP, Consultant Pulmonologist, and Internist, Head Division of Pulmonology, Allergy and Immunology, Director of Bronchoscopy Unit and PFT Lab, Department of Medicine, King Fahad Hospital, Jeddah, Saudi Arabia. Director of Adult Respirology Fellowship Training Program, King Fahad Hospital. Assistant Professor, Rabigh Medical College, King Abdul-Aziz University, Jeddah, Saudi Arabia

\begin{abstract}
Allergic bronchopulmonary aspergillosis (ABPA) is an allergic fungal infection that induces immunoglobulin E (IgE) production and eosinophils proliferation and affect mostly asthmatic and cystic fibrosis patients. The mainstay treatment for ABPA is systemic steroid and antifungal treatment which have increasing rates of treatment failure and side effects. Because of their mechanism of action in suppressing IgE or eosinophils, biologic drugs were expected to play an important role in the treatment of ABPA, however, their use in this issue was off label and lack the evidence. In this comprehensive and comparative review, 59 full text articles (228 patients) were selected. The outcomes were analyzed and the percentages of posttreatment change for each variable in each study were collected then the overall median percentages were calculated for each variable for each biologic drug. Comparative discussion of these outcomes was done in terms of clinical and functional response, reduction of exacerbation events, reduction of IgE level and eosinophils count, prevention of complications and patient's ability to reduce steroid dose or discontinue it. The review shows that the use of biologic drugs for treatment of ABPA is associated with a significant clinical and functional improvement and reduction of exacerbation rates up to $90 \%$. There is more reduction in post-treatment $\operatorname{IgE}$ level with mepolizumab and marked reduction in posttreatment eosinophils count with benralizumab. Mepolizumab has the better steroid-sparing effect. Changing from one biologic drug to another with different target in case of treatment failure is advisable. More stronger studies and randomized control trials are needed to figure out the use of biologic drugs for ABPA treatment.
\end{abstract}

Keywords: Allergic bronchopulmonary aspergillosis; Anti-IgE; Benralizumab; Dupilumab; Mepolizumab

Abbreviations: ABPA: Allergic Bronchopulmonary Aspergillosis; IgE: Immunoglobulin E; ISHAM: International Society for Human and Animal Mycology; IL-5R: Interleukin-5 Receptor; IL-4: Interleukin-4; IL-13: Interleukin-13; ACT: Asthma Control Test

\section{Introduction}

Allergic bronchopulmonary aspergillosis (ABPA) is a disease that occurs due to a hypersensitivity reaction to a fungus named Aspergillus fumigatus that colonize the airways mostly in patients with asthma or cystic fibrosis [1-5]. Between 1-5 \% of asthmatic patients and $1-15 \%$ of cystic fibrosis patients develop ABPA during their disease course especially at advanced disease stages $[1,4,6,7]$. The Aspergillus fugus induces repeated episodes of inflammation and abundant brown mucus production that obstruct bronchial lumen and eventually results in bronchiectasis, fibrosis, and varying degrees of respiratory failure [8]. One of the most widely used diagnostic criteria was that issued by the working group of the International Society for Human and Animal Mycology (ISHAM) (Table 1) [9]. However, there are other diagnostic criteria that are useful and applicable in some health centers and hospitals $[4,10,11]$.
The main goal in the treatment of ABPA is to control the inflammation that is induced by the Aspergillus fumigatus, hence, reducing the disease progression and preventing the development of the non-reversible complications such as bronchiectasis, fibrosis, and respiratory failure [12]. Therefore, steroids were the gold standard and most effective treatment over the past time $[4,13]$. Most patients develop remission with steroid treatment evident by clinical improvement and reduction in serum IgE levels $[14,15]$. However, it has been known that steroids lead to numerous side effects when used for a long period of time limiting their use. Antifungal treatments are used also in cases requiring high doses of steroids but also these have side effects [7,16-18]. Because of the lower response rates in some patients for the standard treatments and because of its side effects too, biological drugs such as omalizumab, mepolizumab, benralizumab and 
dupilumab were proposed to be an alternative (or add on) treatment for ABPA.

These biologic treatments were put in the focus based on their role in inhibition of type 2 inflammation, regulation of eosinophiles and IgE levels and modulation of inflammatory cytokines such as interleukins (e.g., IL-4, IL-5, IL-5R, IL-13) which were also observed in ABPA $[19,20]$. Nevertheless, their use in treatment of ABPA is off label, lack the evidence and has not yet supported by any international guidelines. Most of this evidence

Table 1: Diagnostic criteria for ABPA by the international society for human and animal mycology (ISHAM) (2013). came from case reports, personal trials, and observational studies. In this review I tried to collect and analyzed the relevant data, I highlighted the use of each biologic drug separately, and I made a comparative discussion regarding the outcomes and efficacy between these biologic drugs in terms of clinical and functional response, reduction of exacerbation events, reduction of IgE level and eosinophils count, prevention of complications and patient's ability to reduce steroid dose. To my knowledge, this study is the first comprehensive and comparative review study that figure out this issue in details.

Baseline Conditions: Asthma and/or Cystic Fibrosis

\section{Mandatory Criteria:}

\begin{tabular}{|l|l|l|}
\hline 1 & High IgE specific to A. fumigatus (OR) & $>0.35 \mathrm{kU} / \mathrm{L}$ \\
\hline 2 & A positive skin test against A. fumigatus (AND) & $>1000 \mathrm{UI} / \mathrm{mL}$ \\
\hline 3 & High total serum IgE & $>10$ \\
\hline
\end{tabular}

Other Criteria (at least 2 must be present)

\begin{tabular}{|c|c|c|}
\hline 1 & High IgG against A. fumigatus (OR) & $>27 \mathrm{mg} / \mathrm{L}$ \\
\hline \multirow[t]{6}{*}{2} & Presence of Radiological changes typical of ABPA (OR) & \\
\hline & - Central and proximal cylindrical bronchiectasis & \\
\hline & - Alterations predominantly in the upper lobe & \\
\hline & - Nodules & \\
\hline & - Atelectasis & \\
\hline & - Air trapping & \\
\hline 3 & High total eosinophil count & $>500$ cells $/$ UL \\
\hline & ABPA, allergic bronchopulmonary aspergillosis. & \\
\hline
\end{tabular}

\section{Key Points}

i. System steroids and antifungal treatment are the standard and the first line treatment for ABPA, While the use of biologic drugs in treatment of ABPA is off label and lack the evidence, hence, biologic treatments should be kept for refractory cases unless strong recommendations evolve regarding their use for ABPA. ii. The use of biologic drugs for treatment of ABPA is associated with a significant clinical improvement and reduction of exacerbations up to $90 \%$, although the treatment period required to achieve this was variable between different biologic drugs.

iii. Functional improvement and post-treatment FEV-1 rise were noticed among all biologic drugs but to a lesser extent than clinical improvement. 
iv. There is more reduction in post-treatment IgE level with mepolizumab and marked reduction in post-treatment eosinophils count with benralizumab.

v. Mepolizumab has a higher rate of functional improvement and increase in the ability of patients to reduce the dose of steroids or to discontinue it (steroid sparing effect).

vi. The radiological improvement is an important item to assess disease remission and progression of complications, I encourage all authors to report the radiological follow up of the patients.

vii. Changing from one biologic drug to another with different target in case of treatment failure is advisable based on availability and licensing

viii. Because of the descriptive nature of the reviewed studies that lack the evidence base and the statistical measures, the outcomes of this study should not be relied on completely, however, it gives general baseline and outlines for future decisions.

ix. More stronger studies and randomized control trials with larger number of patients or head-to-head comparative studies are needed to figure out the use of biologic drugs for ABPA treatment with more concentration on improvement assessment items such as clinical, functional, and serological items.

\section{Method}

In September 2021, I have conducted a search using some of available search engines such as but not limited to PubMed, EMBASE, Ovid, Web of science and Google Scholar. At first, I collected a total of 412 studies from all available data (e.g., case series, case reports, observational studies). After close observation I have selected 59 full text articles (228 patients included) that fall within the scope of this study (i.e., studies that report the use of one or more biologic treatments in adult patients being treated with standard treatment with partial response) (Figure 1). Outcomes of these studies were analyzed non-statistically according to the nature of each study and finally the percentages of posttreatment change for each variable in each study were collected then the overall median percentages were calculated for each variable for each biologic drug which were compared with each other (Table 2).

Figure 1: Study Flow Diagram from inception to Sep 2021 (electronic search).

\section{Results}

The resultant outcomes and percentages for each variable for all biologic drugs with the calculated over all percentages were

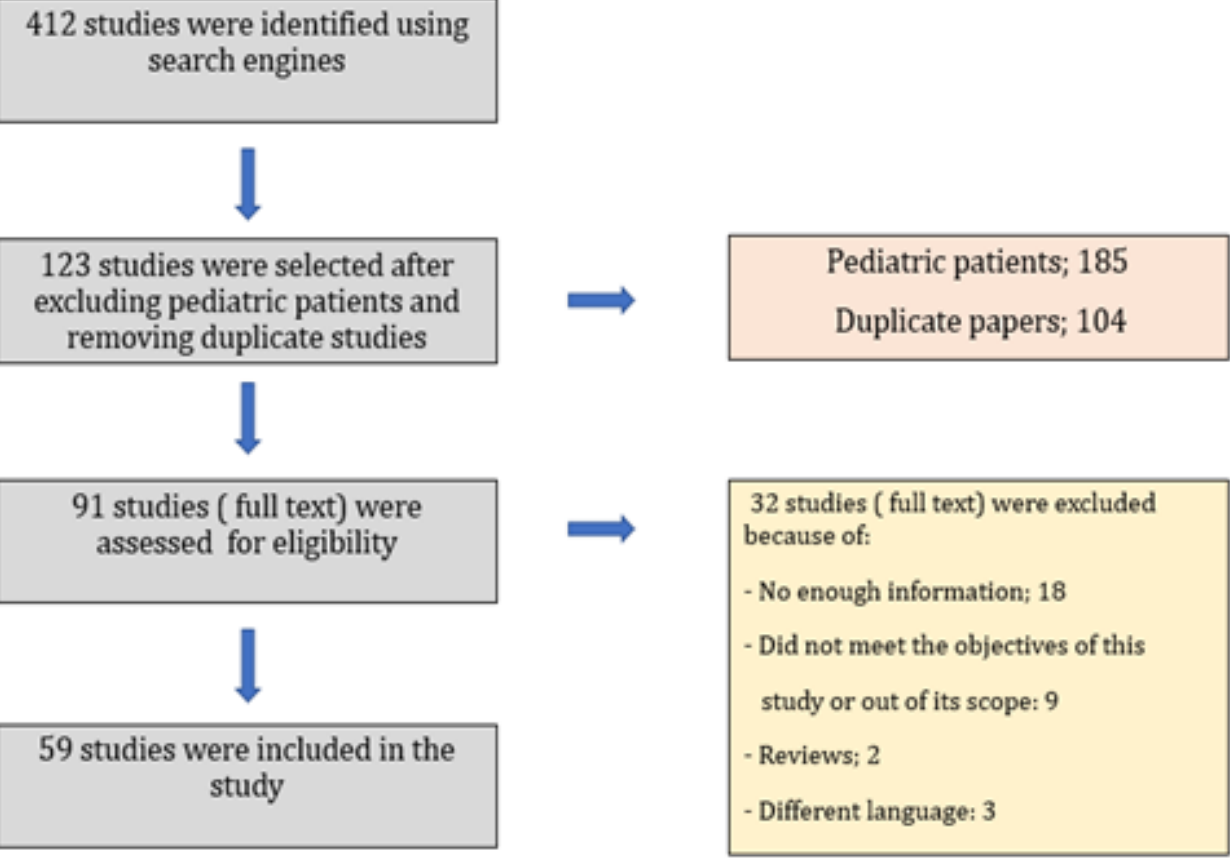

32 studies ( full text) were excluded

Did not meet the objectives of this

tudy or out of its scope: 9

Different language: 3 
International Journal of Pulmonary \& Respiratory Sciences

Table 2: Summary of the reviewed studies for each biologic drug and the calculated median percentages for each outcome variable.

\begin{tabular}{|c|c|c|c|c|c|c|}
\hline Biologic Drug & $\begin{array}{l}\text { No of Studies } \\
\text { Reviewed }\end{array}$ & $\begin{array}{l}\text { No of Patients } \\
\text { Included }\end{array}$ & $\begin{array}{l}\text { Reduction in } \\
\text { IgE Level }\end{array}$ & $\begin{array}{l}\text { Reduction in Eosino- } \\
\text { philes Count }\end{array}$ & $\begin{array}{c}\text { Reduction in Exacerba- } \\
\text { tion Rate }\end{array}$ & $\begin{array}{l}\text { Reduction in } \\
\text { Steroid Use }\end{array}$ \\
\hline Omalizumab & 36 & 133 & $45 \%$ & $70 \%$ & $90 \%$ & $66 \%$ \\
\hline Mepolizumab & 13 & 62 & $67 \%$ & $95 \%$ & $85 \%$ & $98 \%$ \\
\hline Benralizumab & 6 & 7 & $40 \%$ & $99 \%$ & $90 \%$ & $95 \%$ \\
\hline Dupilumab & 4 & 26 & $65 \%$ & $\begin{array}{l}\text { 48\% (initial transient } \\
\text { increase) }\end{array}$ & $85 \%$ & $90 \%$ \\
\hline
\end{tabular}

\section{Omalizumab}

Omalizumab is a recombinant DNA-derived humanized IgG monoclonal antibody that binds to free immunoglobulin E (IgE). It has been approved to treat severe case of asthma since 2003 , thus it was the first approved biologic treatment and has preceded other biologic drugs by many years. In APBS treatment, Omalizumab showed reduction in total IgE by a median of $45 \%$ and reduction in eosinophiles count by a median of $70 \%$ from baseline after a variable period of time ranging from 6 to 36 months according to the study treatment time [21-54]. Omalizumab also led to improvement of lung function and FEV-1 values [21-34, 37-54]. Not surprisingly, up to $66 \%$ of patients who received omalizumab treatment succeed to either reduce steroid dose or suspend it and $90 \%$ of patients had reduced rate of exacerbations for up to 3 years [21-56].

\section{Mepolizumab}

Mepolizumab is a humanized recombinant IgG1 monoclonal antibody that blocks interleukin-5 (IL-5). In ABPA treatment, Mepolizumab led to reduction in the total IgE level by a median of $67 \%$ and reduction in eosinophiles count by a median of $95 \%$ from baseline after a treatment period ranging from 6 to 24 months [57-69]. There was an improvement in lung function and FEV-1 noticed in most studies and there was also a reduction in annual exacerbation rate in $85 \%$ of patients and $98 \%$ of patients were able either to reduce the dose of systemic steroid or stop it [57-69].

\section{Benralizumab}

Benralizumab is a humanized recombinant IgG1 monoclonal antibody that blocks the alpha chain of interleukin-5 receptor (IL-5R). Six studies had addressed the use of benralizumab in the treatment of ABPS. Benralizumab treatment showed a reduction in total IgE by a median of $40 \%$, reduction in eosinophiles count by a median of $99 \%$ over a treatment period of 3 months. The number of exacerbations was also significantly reduced, and patients were able to discontinue steroid after 3 months [70-75].

\section{Dupilumab}

Dupilumab is a humanized recombinant IgG4 monoclonal antibody that blocks interleukin-4 (IL-4) and interleukin-13 (IL13). Four studies reported the use of dupilumab in the treatment of ABPA. Dupilumab treatment showed a reduction in total IgE level by a median of $65 \%$ and in total eosinophiles count by a median of $48 \%$ from baseline over a treatment period of 3 to 6 months [76-79]. FEV-1 has improved in most patients after treatment. There was also a significant reduction in exacerbation rate and most patients were able to discontinue steroid [76-79].

\section{Discussion}

The pathogenesis of allergic bronchopulmonary aspergillosis remains incompletely understood, however, it is presumed that the hypersensitivity reaction to antigens of Aspergillus fumigatus triggers the releases of cytokines and interleukin (e.g., IL-4, IL-5, and IL-13), which interact with eosinophils and IgE in the blood and airways [1-5,83,84]. Based on that and on the illustrated mechanism of actions of different biologic drugs that selectively block this pathway at a specific point, biologic drugs were presumed to play an important role in treatment of ABPA even though they are not approved by any international guidelines for this purpose. [19-20]. In this review I have selected studies that report the use of one or more biologic drug in the treatment of ABPA. I included 59 studies (228 patients) that analyzed the use of Omalizumab, Mepolizumab, Benralizumab and Dupilumab and in both asthmatic and CF patients.

Unsurprisingly, omalizumab use was the predominant and the most frequent (70\%) as it preceded other biologics by many years. Factors such as sex and age distribution were consistent with what has been mentioned in the literature in this regard $[6,30]$. In the review studies, patients with ABPA have elevated baseline IgE levels with $40 \%$ of patients had values over $1000 \mathrm{IU} /$ $\mathrm{mL}$ which is required for ABPA diagnosis as per ISHAM diagnostic criteria (Table 1) [21-36]. Notably, in patients who were treated with omalizumab for ABPA, the baseline median value of IgE was $1500 \mathrm{IU} / \mathrm{mL}$. The dose of omalizumab used to treat severe 
asthma is calculated according to the patient's weight and $\operatorname{IgE}$ levels $(\leqslant 700 \mathrm{IU} / \mathrm{mL})$ with a maximum dose of $750 \mathrm{mg} / \mathrm{month}$. In ABPA, the median baseline of IgE level is much higher (1500 IU/ $\mathrm{mL}$ ), thus the maximum dose of omalizumab was exceeded (375 mg every 2 weeks) and this induced reduction of posttreatment IgE levels by $45 \%$ in most of patients [21-54,85].

The decline in the level of total IgE was related to the baseline level of IgE, in which, patients whose serum IgE >1000 IU/ $\mathrm{ml}$ were more sensitive to omalizumab treatment than those with $<1,000 \mathrm{IU} / \mathrm{ml}$ [37-54]. However, this reduction in IgE level was achieved with treatment over a long period of time (6-36 months) which is supposed to be shorter than this. Exacerbation and relapse after treatment were defined and assessed based on deterioration of clinical status and rise of IgE level by $>50 \%$ from the previous value [28,37-5]. Moreover, the effect of omalizumab on exacerbation was influenced by baseline exacerbation, administration route and length of omalizumab use [28,37-54]. Voskamp and his colleagues carried a self-placebo-controlled randomized trial involved 13 volunteers and found that clinical improvement was accompanied by decreased basophil reactivity to Aspergillus fumigatus [86].

In addition, omalizumab leads to reduction in high-affinity IgE receptor expression on mast cells, basophils, and dendritic cells [86-88]. The median reduction rates in IgE level after treatment were $67 \%$ and $65 \%$ for mepolizumab and dupilumab respectively, which are surprisingly higher than that in omalizumab although both mepolizumab and dupilumab are not working on IgE like omalizumab and the baseline IgE level is not required to initiate them [57-69,76-81]. The median reduction rate in eosinophiles count was higher with bernalizumab (99\%) compared to other biologic drugs [70-75]. In the other hand, the reduction in eosinophils was low in dupilumab (48\%) which is unexpected based on its mechanism of action that inhibit eosinophiles accumulation and proliferation [76-81].

In fact, dupilumab induces transient eosinophils increase after its initiation as it is proposed that dupilumab blocks the migration of eosinophils into airways and therefore increases blood eosinophils transiently, however, this was not associated with clinical symptoms and usually returned to a normal level later on $[78,80,81]$. The posttreatment clinical improvement was observed with all biologic treatment, although the treatment duration was variable between them. Omalizumab and benralizumab have the higher clinical response rates, $90 \%$ for both [21-36,70-74]. The clinical improvement was accompanied by reduction in overall exacerbation rates with all biologic drugs. There was a functional improvement in FEV-1 value after treatment seen with all biologic treatments but was not as significant as expected when correlated to the clinical improvement, and this might be attributed to other confounding factors such as timing of procedure, disease severity and patients' factors.
However, mepolizumab showed the higher rate of functional improvement from the baseline compared to other biologic drugs [57-69]. Majority of patient were able to reduce the maintenance steroid dose or discontinue it, with the higher rate was reported with mepolizumab (98\% of patients), to be the most effective steroid sparing agent among other biologic drugs. [57-69]. The use of combination of two or more biologic drugs or shifting from one to another was described in the literature $[65,72,74,78,79]$. Katsuyoshi et al, reported clearance of ABPA with benralizumab treatment after failed mepolizumab treatment and they related that to the ability of benralizumab to eliminate eosinophils already present in the airways and mucus plugs which was not achieved with mepolizumab [72]. Whereas Mummler et al, reported a successful treatment of ABPA with dupilumab for ABPA resistant to both omalizumab and benralizumab [78].

To tell the truth, radiological improvement is an important tool to assess posttreatment improvement and remission, however, the data regarding this issue was deficient in the reviewed studies, apart from very few studies. For all biologic drugs, there were no major or serious side effects reported through the reviewed studies. The strength points of this review are that it is the first study that discuss this issue comprehensively and made a comparative analysis between the biologic drugs and the large number of related studies that were reviewed. In the other hand, the limitation is that I was unable to do statistical analysis as there is differences in types of studies, number of patients in each study, purpose and endpoints, and absence of important data (e.g., clinical data, asthma control test (ACT) and radiological follow up) in some studies. Therefore, putative selection bias is inevitable.

\section{Conclusion}

This study showed that, in general, the use of biologic drugs for treatment of ABPA is associated with a significant clinical improvement and reduction of exacerbations up to $90 \%$, although the treatment period required to achieve this was variable between different biologic drugs with omalizumab seems to require more time to achieve improvement. Functional improvement and posttreatment FEV-1 rise were also noticed among all biologic drugs but to a lesser extent. Although biologic drugs have different mechanisms of action, there was more reduction in IgE level with mepolizumab and marked reduction in eosinophils count with benralizumab (which can be used as a marker of disease remission). However, mepolizumab dominates in some variables such as higher rate of functional improvement and the ability of patients to reduce the dose of steroids or to discontinue it (steroid sparing effect).

Although the radiological improvement is an important item to assess disease remission and progression of complications, it was not determined because of the paucity of data from the reviewed studies. Meanwhile, as clear from this study and literature review, changing from one biologic drug to another 
with different target in case of treatment failure is advisable based on availability and licensing. Notably, because of the descriptive nature of most of the reviewed studies that lack the evidence base and the statistical measures, the outcomes of this study should not be relied on for which biologic drug is better or which one to initiate first. More stronger studies and randomized control trials with large number of patients or head-to-head comparative studies are needed to figure this out with more concentration on improvement assessment items such as clinical, functional, and serological items.

\section{Acknowledgment}

The author would like to thank his wife Ms. Hessah Albogami for her assistance and support in preparing and reviewing this article and to appreciate her unforgettable efforts.

\section{References}

1. Agarwal R (2009) Allergic bronchopulmonary aspergillosis. Chest 135(3): 805-626.

2. Tillie LI, Tonnel AB (2005) Allergic bronchopulmonary aspergillosis. Allergy 60(8): 1004-1013.

3. Zander DS (2005) Allergic bronchopulmonary aspergillosis: an overview. Arch Pathol Lab Med 129(7): 924-928.

4. Greenberger PA (2002) Allergic bronchopulmonary aspergillosis. J Allergy Clin Immunol. 110(5): 685-692.

5. Patterson K, Strek ME (2010) Allergic bronchopulmonary aspergillosis. Proc Am Thorac Soc 7(3): 237-244.

6. Maturu V, Agarwal R (2015) Prevalence of Aspergillus sensitization and allergic bronchopulmonary aspergillosis in cystic fibrosis: systematic review and meta-analysis. Clin Exp Allergy 45(12): 1765-1778.

7. Patel AR, Patel AR, Singh S, Shantanu S, Imran K (2019) Diagnosing allergic bronchopulmonary aspergillosis: a review. Cureus 11(4): e4550.

8. Stevens DA, Moss RB, Kurup VP, Knutsen AP, Paul G, et al. (2003) Allergic bronchopulmonary aspergillosis in cystic fibrosis--state of the art: Cystic Fibrosis Foundation Consensus Conference. Clin Infect Dis 37 (Suppl 3): S225-S264.

9. Agarwal R, Chakrabarti A, Shah A, Gupta, J, F Meis, et al. (2013) Allergic bronchopulmonary aspergillosis: review of literature and proposal of new diagnostic and classification criteria. Clin Exp Allergy 43(8): 850873.

10. Rosenberg M, Patterson R, Mintzer R, BJ Cooper, M Roberts, et al. (1977) Clinical and immunologic criteria for the diagnosis of allergic bronchopulmonary aspergillosis. Ann Intern Med 86(4): 405-414.

11. Shah A, Panjabi C (2016) Allergic bronchopulmonary aspergillosis: a perplexing clinical entity. Allergy Asthma Immunol Res 8(4): 282-297.

12. Greenberger PA, Bush RK, Demain JG, Luong A, Slavin RG, et al. (2014) Allergic bronchopulmonary aspergillosis. J Allergy Clin Immunol Pract 2(6): 703-708.

13. Fink JN (2000) Therapy of allergic bronchopulmonary aspergillosis. Indian J Chest Dis Allied Sci 42(4): 221-224.

14. Agarwal R, Aggarwal AN, Dhooria S, Singh SI, Garg M, et al. (2016) A randomized trial of glucocorticoids in acute-stage allergic bronchopulmonary aspergillosis complicating asthma. Eur Respir J 47(2): 490-498.
15. Natarajan S, Subramanian P (2014) Allergic bronchopulmonary aspergillosis: A clinical review of 24 patients: Are we right in frequent serologic monitoring? Ann Thorac Med 9(4): 216-220.

16. Tracy MC, Okorie CUA, Foley EA, Richard BM (2016) Allergic bronchopulmonary aspergillosis. J Fungi 2(2): 17.

17. Stevens DA, Schwartz HJ, Lee JY, Moskovitz BL, Jerome DC, et al. (2000) A randomized trial of itraconazole in allergic bronchopulmonary aspergillosis. N Engl J Med 342(11): 756-762.

18. Agarwal R, Dhooria S, Singh SI, Aggarwal AN, Garg M, et al. (2018) A Randomized Trial of Itraconazole vs Prednisolone in Acute-Stage Allergic Bronchopulmonary Aspergillosis Complicating Asthma. Chest 153(3): 656-664.

19. Isabel CE, Saveria S, Eliana IM, Liliana FT (2020) Use of monoclonal antibodies for allergic bronchopulmonary aspergillosis in patients with asthma and cystic fibrosis: literature review. Ther Adv Respir Dis 14: 1753466620961648.

20. Erkoc M, Aydin O, Bavbek S (2021) Biological Treatments in patients with ABPA. Tuberk. Toraks 69(1): 84-93.

21. Da Cunha FS, Valle SOR, Filho JE, Sergio DD, Alfeu TF (2018) Omalizumab as add-on therapy in patients with asthma and allergic bronchopulmonary aspergillosis. J Bras Pneumol 44(5): 439-441.

22. Aguiar R, Fernandes NP, Lopes A, C Lopes (2017) Allergic bronchopulmonary aspergillosis treated successfully with omalizumab. Rev Port Pneumol 23(5): 304-306.

23. Collins J, Devos G, Hudes G, David Rosenstreich (2012) Allergic bronchopulmonary aspergillosis treated successfully for one year with omalizumab. J Asthma Allergy 5: 65-70.

24. Kelso JM (2015) Following total IgE concentration in patients with allergic bronchopulmonary aspergillosis on omalizumab. J Allergy Clin Immunol Pract 4(2): 364-365.

25. Wolf BL, Johnson A (2014) Unexpected decrease in total IgE in a patient with allergic bronchopulmonary aspergillosis treated with omalizumab. J Allergy Clin Immunol Pract 2(1): 111-113.

26. Homma T, Kurokawa M, Matsukura S, Munehiro Y, Mitsuru A (2016) Anti-IgE therapy for allergic bronchopulmonary aspergillosis. J Microbiol Immunol Infect 49(3): 459-463.

27. Bobolea I, Rodriguez CF, Diaz CR, Carlos MM, Ramon VC (2016) Measuring total IgE is useful in detecting exacerbations in patients with allergic bronchopulmonary aspergillosis receiving omalizumab. J Allergy Clin Immunol Pract 4(2): 361-363.

28. Aydin O, Sozener ZC, Soyyigit S, Reşat K, Zeynep G, et al. (2015) Omalizumab in the treatment of allergic bronchopulmonary aspergillosis: one center's experience with 14 cases. Allergy Asthma Proc 36(6): 493-500.

29. Lin RY, Sethi S, Bhargave GA (2010) Measured immunoglobulin E in allergic bronchopulmonary aspergillosis treated with omalizumab. J Asthma 47(8): 942-945.

30. Unal D (2019) Allergic bronchopulmonary aspergillosis: a clinical evaluation of 15 patients and successful omalizumab treatment of five patients. Asthma Allergy Immunol 17(2): 103-110.

31. Voskamp AL, Gillman A, Symons K, Alessandra S, Jennifer MR, et al. (2015) Clinical efficacy, and immunologic effects of omalizumab in allergic bronchopulmonary aspergillosis. J Allergy Clin Immunol Pract 3(2): 192-199.

32. Sastre I, Blanco J, Mata H, F Garcia (2012) A case of allergic bronchopulmonary aspergillosis treated with omalizumab. J Investig Allergol Clin Immunol 22(2): 145-147. 


\section{International Journal of Pulmonary \& Respiratory Sciences}

33. Perez de LLA, Vennera MC, Parra A, J Guallar, M Marin, et al. (2011) Effects of omalizumab in Aspergillus-associated airway disease Thorax 66(6): 539-540.

34. Koutsokera A, Corriveau S, Sykes J, Adele C, Daniel C, et al. (2020) Omalizumab for asthma and allergic bronchopulmonary aspergillosis in adults with cystic fibrosis. J Cyst Fibros 19(1): 119-124.

35. Ashkenazi M, Sity S, Sarouk I, Bat EBA, Adi D, et al. (2018) Omalizumab in allergic bronchopulmonary aspergillosis in patients with cystic fibrosis. J Asthma Allergy 11: 101-107.

36. Lehmann S, Pfannenstiel C, Friedrichs F, Kristina K, Norbert W, et al. (2014) Omalizumab: a new treatment option for allergic bronchopulmonary aspergillosis in patients with cystic fibrosis. Ther Adv Respir Dis 8(5): 141-149.

37. CK Vander Ent, H Hoekstra, GT Rijkers (2007) Successful treatment of allergic bronchopulmonary aspergillosis with recombinant anti-IgE antibody. Thorax 62(3): 276-277.

38. M Jacquelyn, EM Zirbes (2008) Steroid-sparing effect of omalizumab for allergic bronchopulmonary aspergillosis and cystic fibrosis. Pediatr Pulmonol 43(6): 607-610.

39. A Kanu, K Patel (2008) Treatment of allergic bronchopulmonary aspergillosis (ABPA) in CF with anti-IgE antibody (omalizumab) Pediatr Pulmonol 43(12): 1249-1251.

40. A Alcorta (2009) Successful treatment of allergic bronchopulmonary aspergillosis with omalizumab. Allergy 64: 477e478.

41. F Brinkmann, N Schwerk, G Hansen, M Ballmann (2010) Steroid dependency despite omalizumab treatment of ABPA in cystic fibrosis. Allergy 65(1): 134-135.

42. P Lebecque, A Leonard, C Pilette (2009) Omalizumab for treatment of ABPA exacerbations in CF patients. Pediatr Pulmonol 44(5): 516.

43. LM Quintas Vazquez, M Ortiz Piquer, LA Perez De Llano (2009) Effective anti-immunoglobulin-E antibody treatment of a patient with allergic bronchopulmonary aspergillosis. Arch Bronconeumol 45(4): 207.

44. I Randhawa, T Chin, E Nussbaum (2009) Resolution of corticosteroidinduced diabetes in allergic bronchopulmonary aspergillosis with omalizumab therapy: a novel approach. J Asthma 46(5): 445-447.

45. MF Thomas (2009) Life-threatening allergic bronchopulmonary aspergillosis treated with methylprednisolone and anti-IgE monoclonal antibody. J R Soc Med 102(Suppl 1): 49-53.

46. GA Bhargave, RY Lin (2010) Prolonged suppression of IgE levels associated with allergic bronchopulmonary aspergillosis treated with omalizumab. J Allergy Clin Immunol 125(2): AB68.

47. LA Perez de Llano, MC Vennera, A Parra, J Guallar, M Marin, et al. (2011) Effects of omalizumab in Aspergillus-associated airway disease. Thorax 66(6): 539-540.

48. D Hirsch, J Fagin, Great N (2012) Delayed diagnosis of allergic bronchopulmonary aspergillosis in an asthmatic patient on Xolair: a case report. Ann Allergy Asthma \& Immunol 109: A93eA94.

49. MK Elmallah, Leslie H, Robert GH, Cindy C, Pamela MS (2012) Management of patients with cystic fibrosis and allergic bronchopulmonary aspergillosis using anti-immunoglobulin E therapy (omalizumab). J Pediatr Pharmacol Ther 17(1): 88-92.

50. RB Moss (2012) The use of biological agents for the treatment of fungal asthma and allergic bronchopulmonary aspergillosis. Ann N Y Acad Sci 1272: 49-57.

51. C Martorell, C Morales, I Raducan, et al. (2013) Efficacy of omalizumab treatment in allergic bronchopulmonary aspergillosis. Allergy Eur J Allergy Clin Immunol 68: 362-363.

52. AM Zicari, C Celani, G De Castro, R Valerio De B, M Duse (2014) Anti
IgE antibody as treatment of allergic bronchopulmonary aspergillosis in a patient with cystic fibrosis. Eur Rev Med Pharmacol Sci 18(13): 1839-1841.

53. I Bulut, Z Ozseker (2014) Two cases whereby a heavy persistent allergic asthma controlled by omalizumab, and allergic bronchopulmonary aspergillosis coexist. Allergy 69: 527-528.

54. KT Beam, CA Coop (2015) Steroid sparing effect of omalizumab in seropositive allergic bronchopulmonary aspergillosis. Allergy Rhinol 6(2): 143-145.

55. Evans MO, Morris MJ, Coop CA, Sara EE (2015) Omalizumab, an additional therapy for allergic bronchopulmonary aspergillosis. Ann Allergy Asthma Immunol 115(3): 250-251.

56. Tillie Leblond I, Leroyer C, Germaud P, et al. (2011) Allergic bronchopulmonary aspergillosis and omalizumab. Allergy 66: 12521259.

57. Soeda S, To M, Kono Y, et al. (2019) Case series of allergic bronchopulmonary aspergillosis treated successfully and safely with long-term mepolizumab. Allergol Int 68(3): 377-379.

58. Hirota S, Kobayashi Y, Ishiguro T, Takashi N, Naho K, et al. (2019) Allergic bronchopulmonary aspergillosis successfully treated with mepolizumab: case report and review of the literature. Respir Med Case Rep 26: 59-62.

59. Tsubouchi H, Tsuchida S, Yanagi S, Takafumi S, Mariko M, et al (2019) Successful treatment with mepolizumab in a case of allergic bronchopulmonary aspergillosis complicated with nontuberculous mycobacterial infection. Respir Med Case Reports 28: 100875.

60. Terashima T, Shinozaki T, Iwami E, Takahiro N, Tatsu M (2018) A case of allergic bronchopulmonary aspergillosis successfully treated with mepolizumab. BMC Pulm Med 18(1): 53

61. Kubena P, Duchna H, Capova G, et al. (2018) Allergic bronchopulmonary aspergillosis (ABPA) description of typical exacerbation. Classical remission induction and implementation of mepolizumab. Respiration 95: 488.

62. Altman M, Lenington J, Bronson S, Andrew GA (2017) Combination omalizumab and mepolizumab therapy for refractory allergic bronchopulmonary aspergillosis. J Allergy Clin Immunol Pract 5(4): 1137-1139.

63. Florence S, Elleni SV, Charles P, Olivier V, Jean LH, et al. (2020) Mepolizumab for allergic bronchopulmonary aspergillosis: report of 20 cases from the Belgian Severe Asthma Registry and review of the literature. J Allergy Clin Immunol Pract 8(7): 2412-2413.e2.

64. Oda N, Miyahara N, Senoo S, Junko I, Akihiko T, et al. (2018) Severe asthma concomitant with allergic bronchopulmonary aspergillosis successfully treated with mepolizumab. Allergol Int 67(4): 521-523.

65. Patel J, Ayars AG, Rampur L, Stephen B, Matthew CA (2018) Combination anti-IgE and anti-IL5 therapies in patients with severe persistent asthma and allergic bronchopulmonary aspergillosis (ABPA). J Allergy Clin Immunol 141(2): AB234.

66. Matsumoto N, Shigekusa T, Matsuo A, Tsubouchi H, Yanagi S, et al. (2019) Allergic bronchopulmonary aspergillosis complicated by eosinophilic chronic rhinosinusitis successfully treated with mepolizumab. Respirol Case Rep 7(7): e00465.

67. Tolebeyan A, Mohammadi O, Vaezi Z, Afshin A (2020) Mepolizumab as Possible Treatment for Allergic Bronchopulmonary Aspergillosis: A Review of Eight Cases. Cureus 12(8): e9684.

68. Florence S, Elleni SV, Charles P, Olivier V, Jean LH, et al. (2020) Mepolizumab for allergic bronchopulmonary aspergillosis: Report of 20 cases from the Belgian Severe Asthma Registry and review of the literature. J Allergy Clin Immunol Pract 8(7): 2412-2413.e2. 
69. M Boyle, Siobhain M, Sue M, Sona V, Natalia P, et al. (2020) Mepolizumab use in cystic fibrosis-associated allergic bronchopulmonary aspergillosis. Respirology Case Reports. 9 (1): e00696.

70. Wong S, Ahluwalia S (2019) Benralizumab for the treatment of refractory allergic bronchopulmonary aspergillosis. Ann Allergy Asthma Immunol 123(5): S100-S101.

71. Soeda S, Kono Y, Tsuzuki R, Satoshi Y, Otohiro K, et al. (2019) Allergic bronchopulmonary aspergillosis successfully treated with benralizumab. J Allergy Clin Immunol Pract 7(5): 1633-1635.

72. K Tomomatsu, Y Sugino, N Okada, Jun T, Tsuyoshi O, et al. (2020) Rapid clearance of mepolizumab-resistant bronchial mucus plugs in allergic bronchopulmonary aspergillosis with benralizumab treatment Allergology International 69(4): 636-638.

73. Kazuya T, Masako AO, Shigesato I, Yuki O, Katsuhiro I, et al. (2021) A case of allergic bronchopulmonary aspergillosis with marked peripheral blood eosinophilia successfully treated with benralizumab. Respir Med Case Rep 32: 101339.

74. Bernal RL, B dela H Caballer, C Almonacid S, D Gonzalez de O (2020) Successful treatment of allergic bronchopulmonary aspergillosis with benralizumab in a patient who did not respond to omalizumab, J Investig Allergol Clin Immunol 30(5): 378-379.

75. Hiroaki M, Keiichi F, Hiroki O, Kiriko O, Tadahiro K, et al (2021) Successful Treatment with Benralizumab for Allergic Bronchopulmonary Aspergillosis That Developed after Disastrous Heavy Rainfall in Western Japan. Intern Med 60(9): 1443-1450.

76. Ramonell R, Lee F, Swenson C, Merin K (2020) Dupilumab treatment for allergic bronchopulmonary aspergillosis: a case series. J Allergy Clin Immunol Pract 8(2): 742-743.

77. Corren J, Sher L, Zhu X, M Rice, Y Deniz, et al. (2019) Dupilumab efficacy in patients with uncontrolled, moderate to severe asthma and serologic evidence of allergic bronchopulmonary aspergillosis. Ann Allergy Asthma Immunol 123(5): S15.

78. Carlo M, Bernd K, Jurgen B, Nikolaus K, Katrin M (2020) Differential response to biologics in a patient with severe asthma and ABPA: a role for dupilumab? Allergy Asthma Clin Immunol 16: 55
79. Sunao M, Takeshi S, Yuki Y, Miku O, Manabu I, et al. (2021) Successful Treatment of Mepolizumab- and Prednisolone-resistant Allergic Bronchopulmonary Aspergillosis with Dupilumab. Intern Med 60(17): 2839-2842.

80. Castro M, Corren J, Pavord ID, Maspero J, Wenzel S, et al. (2018) Dupilumab Efficacy \& Safety in Moderate-to-Severe Uncontrolled Asthma. N Engl J Med 378(26): 2486-2496.

81. Rabe KF, Nair P, Brusselle G, Maspero JF, Castro M, et al. (2018) Efficacy \& safety of dupilumab in glucocorticoid-dependent severe asthma. N Engl J Med 378(26): 2475-2485.

82. Oguma T, Taniguchi M, Shimoda T, Kamei K, Matsuse H, et al. (2018) Allergic bronchopulmonary aspergillosis in Japan: A nationwide survey. Allergol Int 67(1): 79-84.

83. Gago S, Denning DW, Bowyer P (2019) Pathophysiological aspects of Aspergillus colonization in disease. Med Mycol 57(Supplement-2): S219-S227.

84. Agarwal R, Sehgal IS, Dhooria S, Ashutosh NA (2016) Developments in the diagnosis and treatment of allergic bronchopulmonary aspergillosis. Expert Rev Respir Med 10(12): 1317-1334

85. AL Voskamp, A Gillman, K Symons, Alessandra S, Jennifer MR, et al. (2015) Clinical efficacy and immunologic effects of omalizumab in allergic bronchopulmonary aspergillosis. J Allergy Clin Immunol Pract 3(2): 192-199.

86. C Prussin, DT Griffith, KM Boesel, Henry L, Barbara F, et al. (2003) Omalizumab treatment downregulates dendritic cell FcepsilonRI expression. J Allergy Clin Immunol 112(6): 1147-1154.

87. D Mac Glashan, HZ Xia, LB Schwartz, J Gong (2001) IgE-regulated loss, not IgE regulated synthesis, controls expression of FcepsilonRI in human basophils. J Leukoc Biol 70(2): 207-218.

88. HJ Gould, BJ Sutton (2008) IgE in allergy and asthma today. Nat Rev Immunol 8(3): 205-217.

\section{Your next submission with Juniper Publishers} will reach you the below assets

- Quality Editorial service

- Swift Peer Review

- Reprints availability

- E-prints Service

- Manuscript Podcast for convenient understanding

- Global attainment for your research

- Manuscript accessibility in different formats

( Pdf, E-pub, Full Text, Audio)

- Unceasing customer service

Track the below URL for one-step submission https://juniperpublishers.com/online-submission.php 